\title{
Probabilistic Analysis of Cut-Slope Stability for Tropical Red Clay of Depok, West Java as an Effect of Rainfall Duration and Intensity
}

\author{
Fathiyah Hakim Sagitaningrum ${ }^{1 *}$, Widjojo Adi Prakoso², and Erly Bahsan ${ }^{2}$ \\ ${ }^{1}$ Graduate Student, Department of Civil Engineering, Universitas Indonesia, Depok 16424, Indonesia \\ ${ }^{2}$ Department of Civil Engineering, Universitas Indonesia, Depok 16424, Indonesia
}

\begin{abstract}
Landslide in Indonesia, specifically in Java island, occurs during rainy seasons. In Java island, it is known that the tropical red clay has the ability to stand at steep angles, while in stability analysis due to rainfall, practitioners only consider the rise of groundwater table. Previous studies states that one of the factor affecting factor of safety (FS) for tropical red clay slopes is the formation of saturated zones due to matric suction. This research studies the effect of rainfall intensity and duration to FS of cut-slopes as parametric study with probabilistic analysis for different height of $10 \mathrm{~m}, 20 \mathrm{~m}$, and $30 \mathrm{~m}$ also slope angles of $27^{\circ}, 45^{\circ}, 55^{\circ}$, and $70^{\circ}$. Rainfall parameter are taken from FTUI rainfall station for advanced pattern and three-days duration of rain. Analysis of seepage uses SEEP/W and slope stability uses SLOPE/W. It is known that the significant increase of probability of failure due to the three-days rainfall is achieved at the $10 \mathrm{~m}$ height and $70^{\circ}$-angled slope. Increase of the probability of failure is mainly due to rainfall infiltration which saturates the surface and pore water pressure increase until certain time where infiltration stops and turn into surface run-off.
\end{abstract}

\section{Introduction}

In Indonesia, according to National Board of Disaster Management (BNPB) landslide data throughout 20132016, there are at least 184 landslides happened in West Java, for example, whereas 150 landslides out of the 184 landslides occurred due to the effect of rainfall and unstable structure of the soil.

Rainfall intensity is one of the primary factor of landslides causes [1]. This is closely related to the condition of Indonesia as one of the tropical nations which have high intensity rainfall. In the concept of unsaturated soil mechanics, sudden high intensity rainfall would infiltrate the soil and reduces the matric suction.

Cut-slopes in Indonesia, under the guidelines for excavated slope or cut-slopes in volcanic and residual soil by the Ministry of Public Works, accommodates only the change of groundwater table for rainfall effect [2]. This method is not entirely suitable to all cases whereas one of the causes of landslides caused by rainfall is due to the formation of saturated zones near the ground surface [3, 4].

The aim of the research is to examine the effect of rainfall intensity and duration as well as the effect of variation of cut-slope geometry to the factor of safety (FS) of the tropical red clay as one of the typical residual soil found in Java.

\section{Literature Review}

\subsection{Unsaturated Soil}

The concept of unsaturated soil stated that soil is not in a fully saturated condition which explains that there is negative pore water pressure above the groundwater table level. Negative value of the pore water pressure is due to the existence of matric suction, which is a reaction of cohesion-adhesion that fills in between the soil particle due to the existence of both air and water at the same time (e.g [5]).

The void in unsaturated soil consists of two components, matric suction and osmotic suction, which changes the formulation of shear strength, seepage, and volume change of soil above the ground water level. Matric suction also gives changes in the formulation of volumetric water content and hydraulic conductivity function which is shown in Soil-Water Characteristic Curve (e.g.: [5]).

\subsection{Tropical Red Clay}

Tropical red clay is one of the residual soil group type which is usually found in Sumatera and Java island as one of the unique soil which can stand still at an angle more than $45^{\circ}$. Wesley categorized the residual soil with

\footnotetext{
* Corresponding author: fathiyah.hakim@gmail.com
} 
Plasticity Index and Liquid Limit from the Atterberg Limit tests as below [4]:

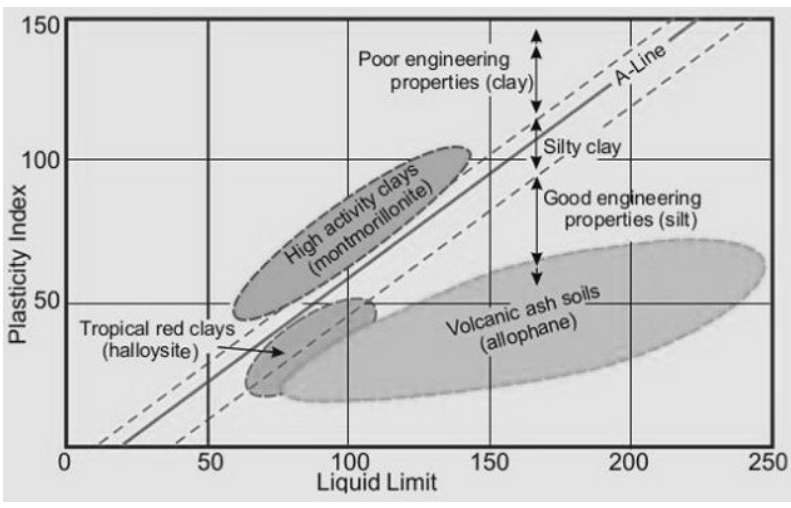

Fig. 1. Plasticity graph for residual soil classification [4]

It is known that in Wesley's previous studies, the mineral composition and soil formation of residual soil allows the groundwater table elevation to rise quickly during rainfall which reduces the FS of slopes quite fast [6]. Research of Tohari and Sarah in Syahbana et al otherwise stated that the main reason of slope stability failure is due to the saturated zones forming inside the body of the slope [3]. Other notes taken for the tropical red clay soil is the slip surface failure which is usually translational and near to zero probability for deep-seated [4].

\subsection{Infiltration and Infiltration Rate Function}

Infiltration is tightly related to rainfall, which is usually defined as rainfall intensity $(\mathrm{mm} / \mathrm{hr})$. Some factors affecting the infiltration rate are hydraulic properties, storage capacity of soil, soil property, rainfall intensity, and infiltration rate of antecedent rainfall [8].

At certain conditions, when rainfall intensity exceeds the soil's infiltration capacity, rainfall will no longer infiltrates into the soil, but turned into surface run-off instead. At this transient condition, the pore water pressure of the surface is defined as zero [9].

\subsection{Probabilistic Assessment}

In slope stability analysis, the parameters used to formulate the safety factor are full of uncertainties. This leads to illogical results for applying the formulated safety factor. The probabilistic assessment and reliability analysis approach are methods which develops rationally to accommodate the uncertainties of various sources and estimate the probability of calculating performance in a systematic order [8].

One of the parameters which affects the probabilistic and reliability analysis method are geotechnical parameters in certain distribution functions, such as normal and lognormal distribution. The calculated safety factor is then distributed according to the function, generating not only the number of the safety factor, but also the probability of failure of the slope in forms of percentage and reliability index [9].
The software in this research, SLOPE/W accommodates the Monte-Carlo simulation method where the uncertain parameters taken into account are unit weight and shear strength parameters (cohesion and friction angle). In SLOPE/W, the number of probability of failure of the slope is defined as the percentage of the Probability Density Function (PDF) area of the calculated safety factor under the value of 1.0 .

\subsection{Related Studies}

For comparison with previous studies of slope stability due to rainfall in different geometry conditions, Huat et al study of unsaturated slope stability chart is taken into account [7].

Huat et al study concerns the Malaysia residual soil which is simplified into a coupling analysis of SEEP/W and SLOPE/W. Huat et al calculates the FS of a slope after a 24-hr rainfall with factors affecting the formulation of the FS are slope angle variation $\tan \beta$, slope height, effective friction angle of the slope $\left({ }^{\circ}\right)$, ratio of suction friction angle and effective friction angle $\left(\phi^{b} / \phi^{\prime}\right)$, dimensionless unit of $c^{\prime} / \gamma H$, and groundwater table condition according to rainfall analysis from SEEP/W. The formulation of the FS of the slope is then calculated as [7]:

$$
F=f-s \tan \phi^{b}
$$

As $\mathrm{F}$ is the FS of the slope after 24-hr rainfall, $\mathrm{f}$ and $\mathrm{s}$ as the stability coefficient, and $\phi^{b}$ as the suction friction angle of the soil $\left({ }^{\circ}\right)$. In the formulation, it is known that after 24-hr rainfall, the higher the slope height, the bigger the value of $f$ and $s$ which indicates that the FS formulated will become higher.

\section{Research Method}

\subsection{Soil Parameters and Slope Geometry}

The soil material in this study is taken to be a homogenous silty clay material type of tropical red clay which are classified according to Fig.1 in an unsaturated condition of $60 \%$ water content and saturated hydraulic conductivity of $1 \times 10^{-9} \mathrm{~m} / \mathrm{s}$. The index parameter properties are taken from Wesley [10] while the shear strength parameter is taken from Triaxial CU data around Depok, West Java and are distributed into a normal distribution function truncated at $2 \sigma$ from its mean value. Particularly, for the means of comparing the slope in different geometry, a dimensionless unit of $c^{\prime} / \gamma H=0.05$ is used for determining the effective cohesion of each slope height. The overall property of the tropical red clay of Depok, West Java, is taken as Table 1 below: 
Table 1. Summary of soil parameters

\begin{tabular}{|c|c|c|c|c|}
\hline & \multicolumn{3}{|c|}{ Slope Height } \\
\hline & & $10 \mathrm{~m}$ & $20 \mathrm{~m}$ & $30 \mathrm{~m}$ \\
\hline \multirow{3}{*}{$\begin{array}{l}\text { Effective } \\
\text { Cohesion }\end{array}$} & $c^{\prime}(\mathbf{k P a})$ & 9 & 18 & 27 \\
\hline & COV & $44.97 \%$ & $44.97 \%$ & $44.97 \%$ \\
\hline & $\begin{array}{l}\text { Standard } \\
\text { Deviation }\end{array}$ & 4.05 & 8.09 & 12.14 \\
\hline \multirow{3}{*}{$\begin{array}{c}\text { Effective } \\
\text { Friction } \\
\text { Angle }\end{array}$} & $\phi^{\prime}\left({ }^{\circ}\right)$ & $23^{\circ}$ & $23^{\circ}$ & $23^{\circ}$ \\
\hline & $\mathrm{COV}$ & $23.49 \%$ & $23.49 \%$ & $23.49 \%$ \\
\hline & $\begin{array}{l}\text { Standard } \\
\text { Deviation }\end{array}$ & 5.4 & 5.4 & 5.4 \\
\hline \multicolumn{2}{|c|}{ Soil Type } & \multicolumn{3}{|c|}{ Silty Clay } \\
\hline \multicolumn{2}{|c|}{$\gamma_{\text {wet }}\left(\mathbf{k N} / \mathbf{m}^{3}\right)$} & \multicolumn{3}{|c|}{$18 \mathrm{kN} / \mathrm{m}^{3}$} \\
\hline \multicolumn{2}{|c|}{$\phi^{\mathbf{b}}\left({ }^{0}\right)$} & \multicolumn{3}{|c|}{$10^{\circ}$} \\
\hline
\end{tabular}

The unsaturated condition, is assumed to be in the function of silty clay soil for Fredlund-Xing estimation and without any residual water content. The matric suction function of volumetric water content and hydraulic conductivity of SEEP/W is set as a range from $0.01 \mathrm{kPa}$ to $100 \mathrm{kPa}$.

As for the slope geometry, the height of $10 \mathrm{~m}, 20 \mathrm{~m}$, and $30 \mathrm{~m}$ are taken with various angles such as $27^{\circ}, 45^{\circ}$, $55^{\circ}$, and $70^{\circ}$. The geometries taken are considered as typical geometry of cut-slope for road constructions around West Java according to [3, 11]. The geometry of the model taken in consideration is as shown in Fig.2.

From Fig.2, the definition of $\mathrm{H}$ is the height of the slope, which are differentiated into $10 \mathrm{~m}, 20 \mathrm{~m}$, and $30 \mathrm{~m}$, $1 / 2 \mathrm{H}$ is the elevation for groundwater table which is considered at a quite deep elevation as a distinct characteristic of slope for tropical red clay, $2 \mathrm{H}$ is the elevation of hard soil, and L is the width of slope according to the angle of the slope which is noted as $\alpha$.

\subsection{Boundary Condition}

The analysis uses a coupling program of SEEP/W and SLOPE/W. The boundary conditions for SEEP/W is differentiated in steady-state conditions where all the boundaries in Fig.2 is considered, assumed as the initial condition of the slope, and transient conditions where only the rainfall intensity is considered with no ponding formed. The pore water pressure is reviewed at two points, as in Fig.2, at point 2-8 and 3-9. For the $\mathrm{SLOPE} / \mathrm{W}$, slope stability is reviewed with the entry-exit method which spans from point 1 to the middle of line 23 as the entry range and point 4 to the middle of line 2-3 as the exit range with Bishop analysis.

\subsection{Rainfall Parameters}

The rainfall parameter is taken form Faculty of Engineering, Universitas Indonesia rain station for a three-days rainfall period. To acquire the rainfall pattern, the rainfall data from July 2014 - March 2015 are divided into a three-days rainfall for each month. The three-days rainfall are taken into consideration where in Java island, a consecutive rainfall from three days are very rare but still have a possibility of happening [4].

The three-days rainfall then divided into 36 intervals which accommodates a two-hourly average rainfall. As for the intensity value, the rainfall intensity is taken from the 24-hour rainfall of 10 years return period from the rain station. The value is then taken as the highest intensity from the three-days rainfall and the rainfall distribution, named as advanced pattern because the highest intensity is achieved at the first day of the three-days rainfall, is as shown in Fig.3.

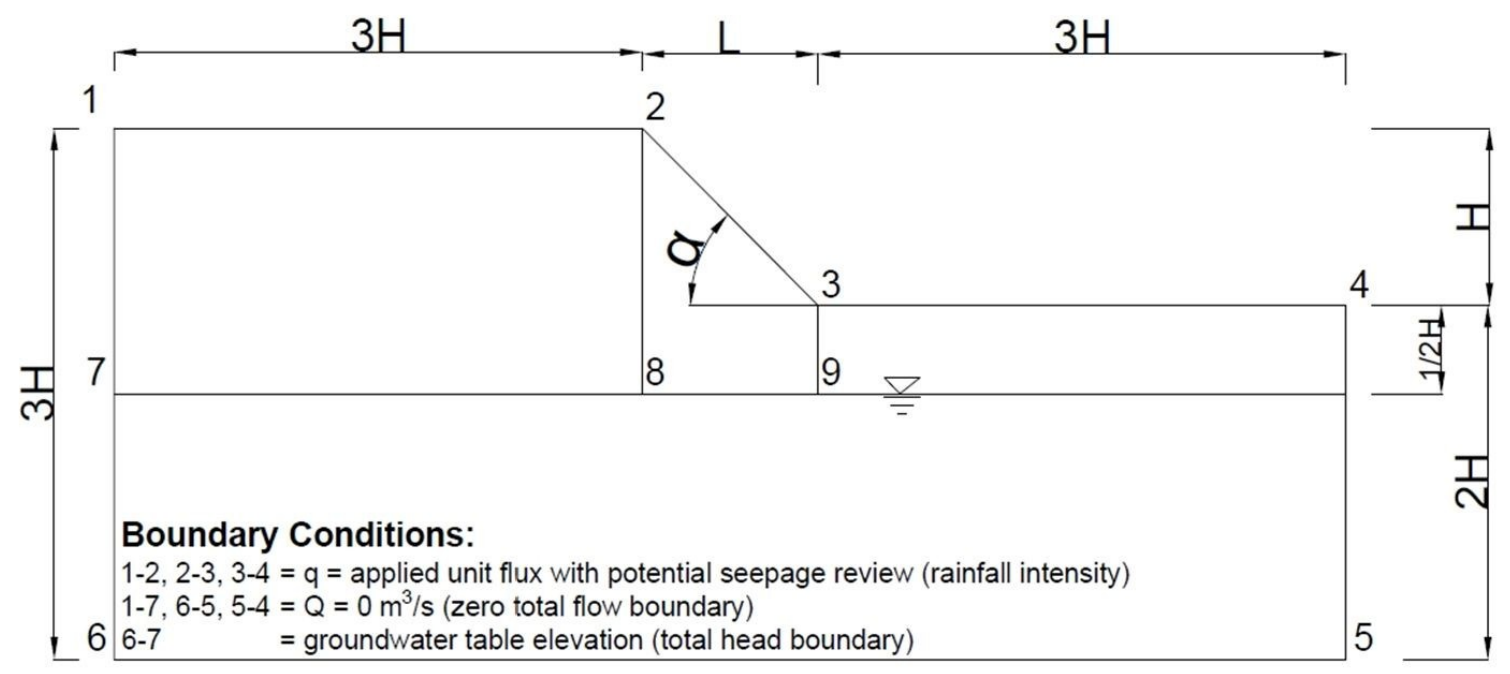

Fig.2. Slope Geometry and boundary conditions for the numerical model 

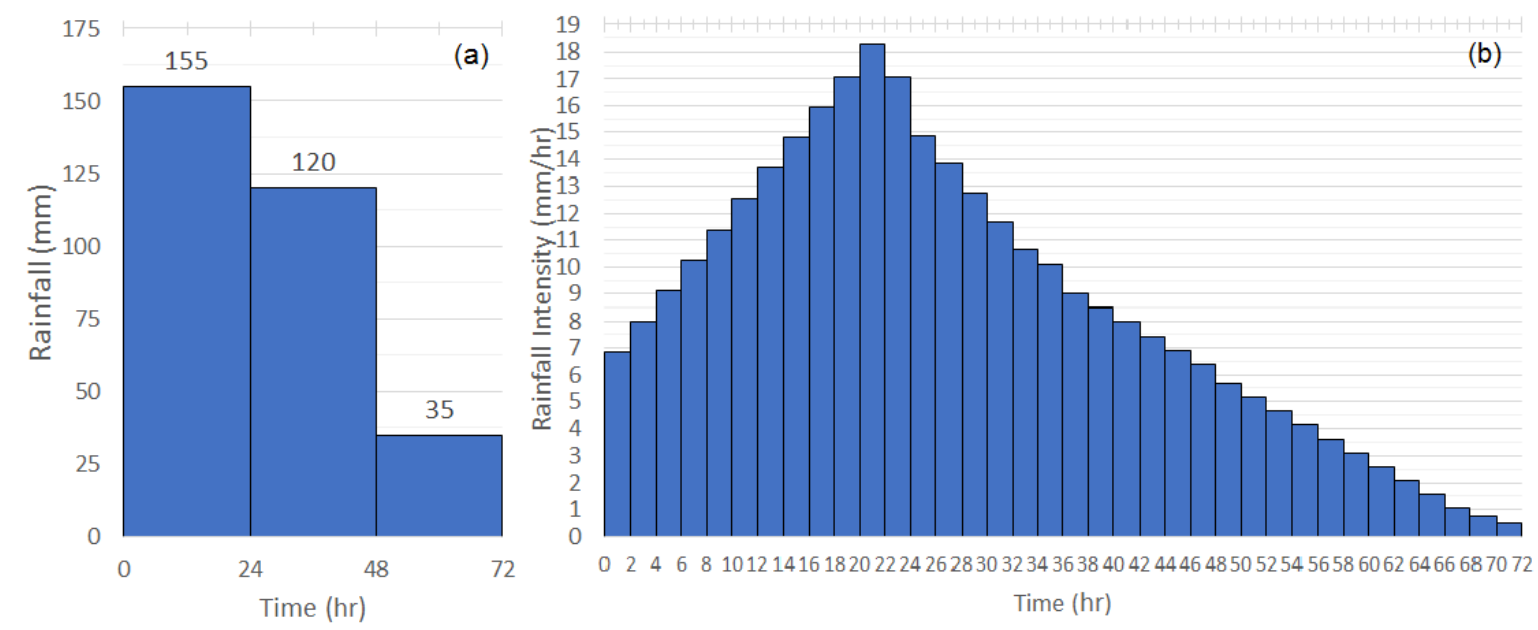

Fig.3. Advanced rainfall pattern for (a) daily and (b) hourly distribution

\section{Results and Analysis}

\subsection{Comparison between change of slope angle and probability of failure}

For each height of slope, taken $10 \mathrm{~m}, 20 \mathrm{~m}$, and $30 \mathrm{~m}$, the change of the slope's probability of failure every 12 hour of the rainfall duration for each slope angle is reviewed. The results are shown below:

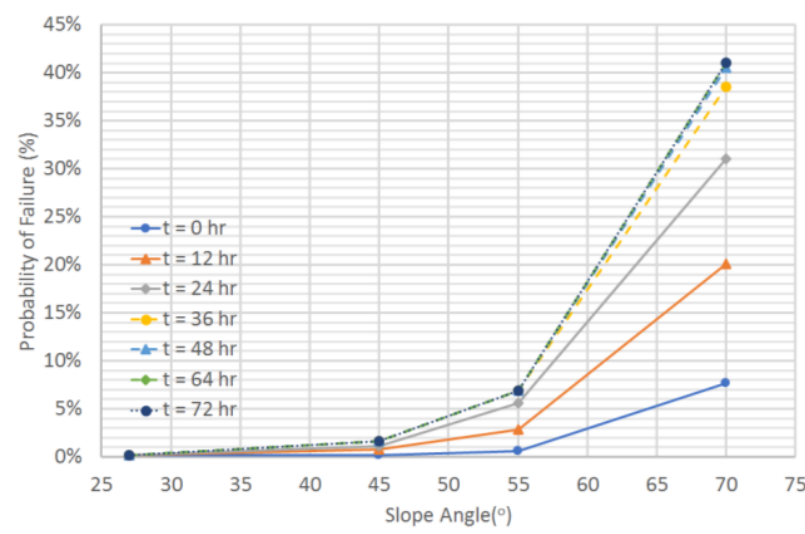

Fig. 4. Probability of failure through time for different angle at $10 \mathrm{~m}$ height

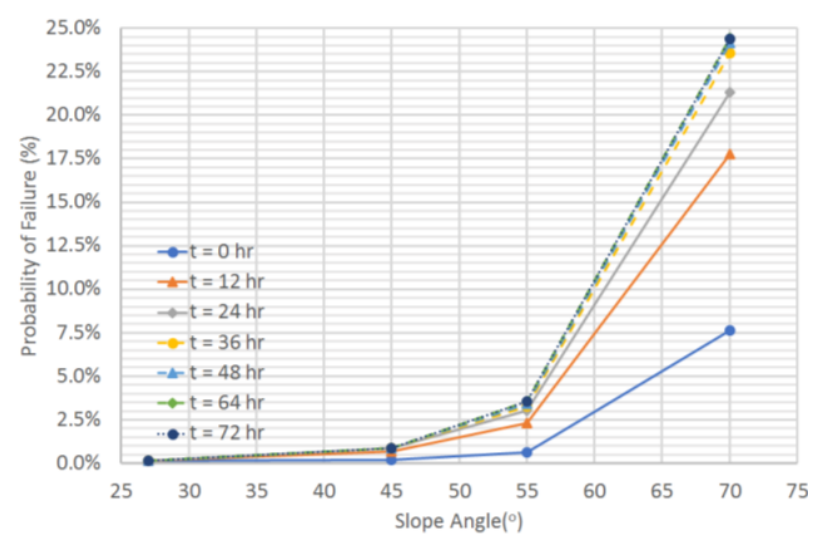

Fig. 5. Probability of failure through time for different angle at $20 \mathrm{~m}$ height

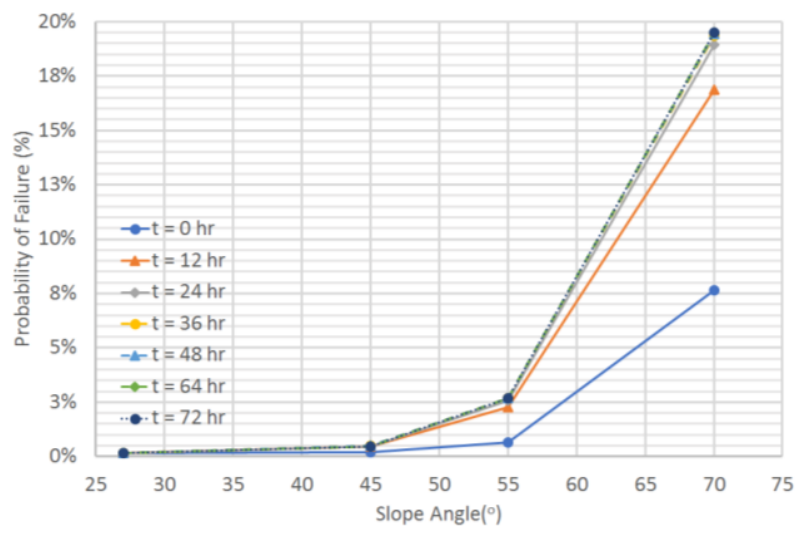

Fig. 6. Probability of failure through time for different angle at $30 \mathrm{~m}$ height

From Fig.4, Fig.5, and Fig.6, it is known that the behaviour for each of the height of the slope is the same. For each height, the increase of initial probability of failure of the slope is directly proportional with the increase of the angle of the slope which indicates that the steeper the slope, the greater the probability of the slope to fail.

It is also known that the most significant change of the probability of failure during rainfall is achieved at the $70^{\circ}$ slope angle. The probability of failure significantly increases at the first 24 hours, different for $30 \mathrm{~m}$ height that increases significantly at the first 12 hours, and become stagnant at the end of the rainfall. This observed behaviour is proportional with the behaviour of the rainfall where the highest intensity is at the first 24 hours and no longer receive high intensity rainfall after it.

Lastly, it is known that the value of $c^{\prime} / \gamma H$ takes effect on the value of the probability of failure of the slope. In order to achieve the $c^{\prime} / \gamma H$ value for each height, the cohesion value of higher slopes is increased. This condition resulted into a lower probability of failure which means that the rise of cohesion value and height of slope is not uniform. 


\subsection{Comparison between change of slope height and probability of failure}

For each angle of slope, taken $27^{\circ}, 45^{\circ}, 55^{\circ}$, and $70^{\circ}$, the change of the slope's probability of failure every 12 hour of the rainfall duration for each slope height is reviewed. The results are shown as below:

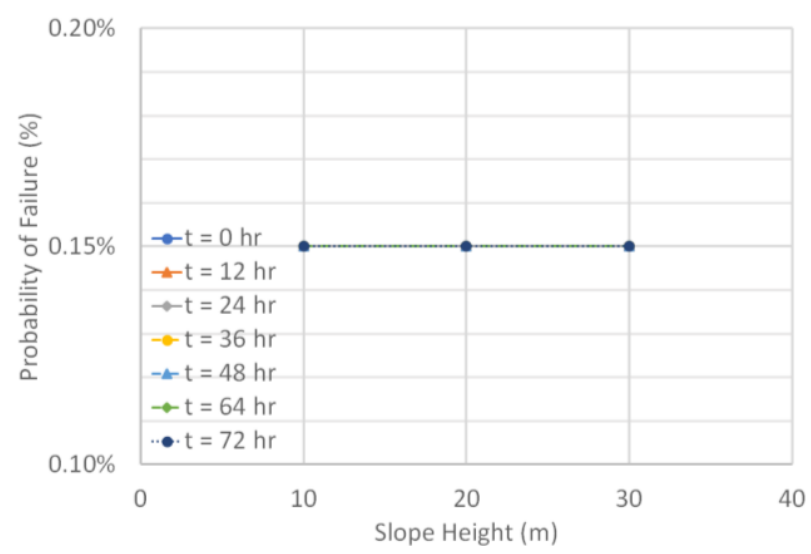

Fig. 7. Probability of failure through time for different height at slope angle $27^{\circ}$

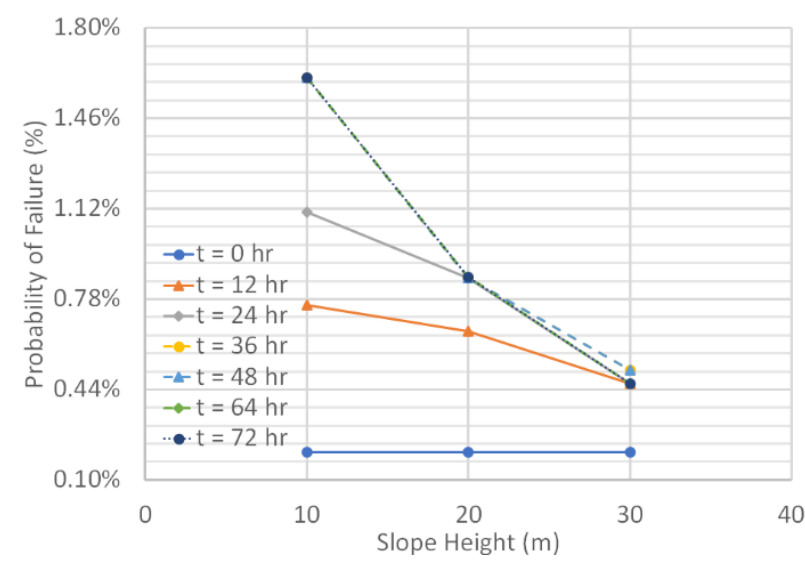

Fig. 8. Probability of failure through time for different height at slope angle $45^{\circ}$

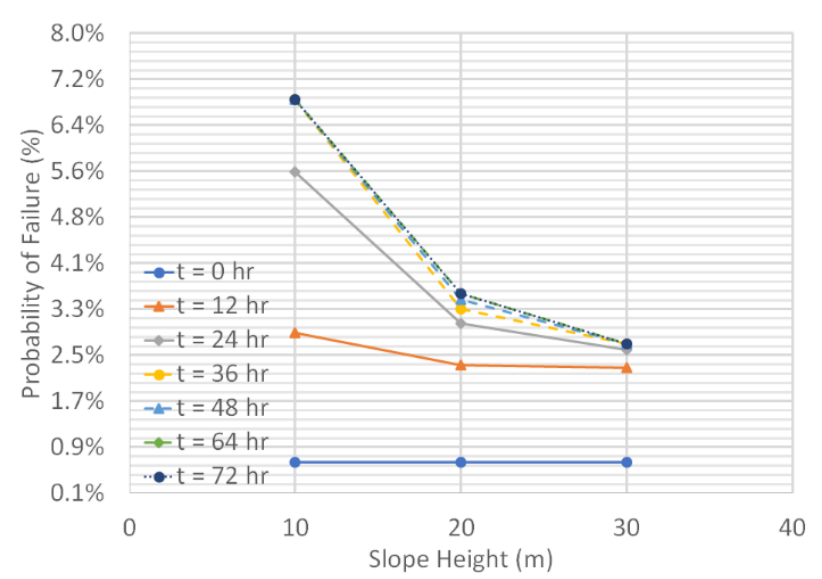

Fig. 9. Probability of failure through time for different height at slope angle $55^{\circ}$

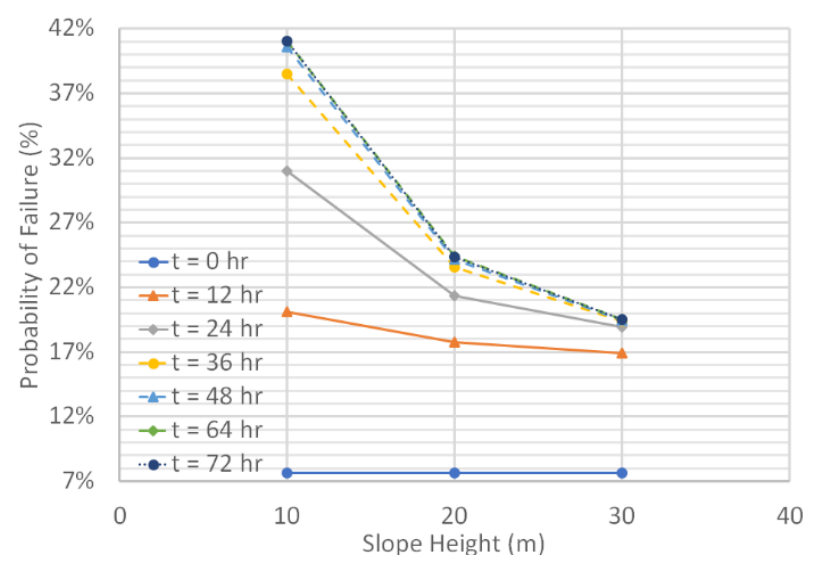

Fig. 10. Probability of failure through time for different height at slope angle $70^{\circ}$

From Fig.7, Fig.8, Fig.9, and Fig.10, it is known that the behaviour for each of the height of the slope is the same. For each height, the increase of initial probability of failure of the slope is directly proportional with the increase of the angle of the slope which indicates that the steeper the slope, the greater the probability of the slope to fail.

It is also known that the initial value of probability of failure of each slope height at each angle is the same. This is due to the given geometry of the slope in the stated $c^{\prime} / \gamma H$ and geometry boundary of this research which gives proportional ratio of vertical and horizontal of the slope resulting in different value of FS, but the same value of probability of failure.

Lastly, it is known that the most significant change of the probability of failure during rainfall is achieved at the $70^{\circ}$ slope angle. The probability of failure significantly increases at the first 24 hours, different for $30 \mathrm{~m}$ height that increases significantly at the first 12 hours, and become stagnant at the end of the rainfall. This is proportional with the behaviour of the rainfall where the highest intensity is at the first 24 hours and no longer receive high intensity rainfall after it.

\subsection{Comparison between change of pore water pressure and slope height}

From the two sections above, it is known that the most significant change of probability of failure is achieved at the $70^{\circ}$ slope angle and the height of $10 \mathrm{~m}$. In examining the highest probability of failure significant change of 10 $\mathrm{m}$ height, the pore water pressure profile during rainfall is considered.

The pore water pressure profile to be reviewed is taken at the $70^{\circ}$ slope angle for each height of $10 \mathrm{~m}, 20 \mathrm{~m}$, and $30 \mathrm{~m}$ every 12 hour. The results are shown below: 


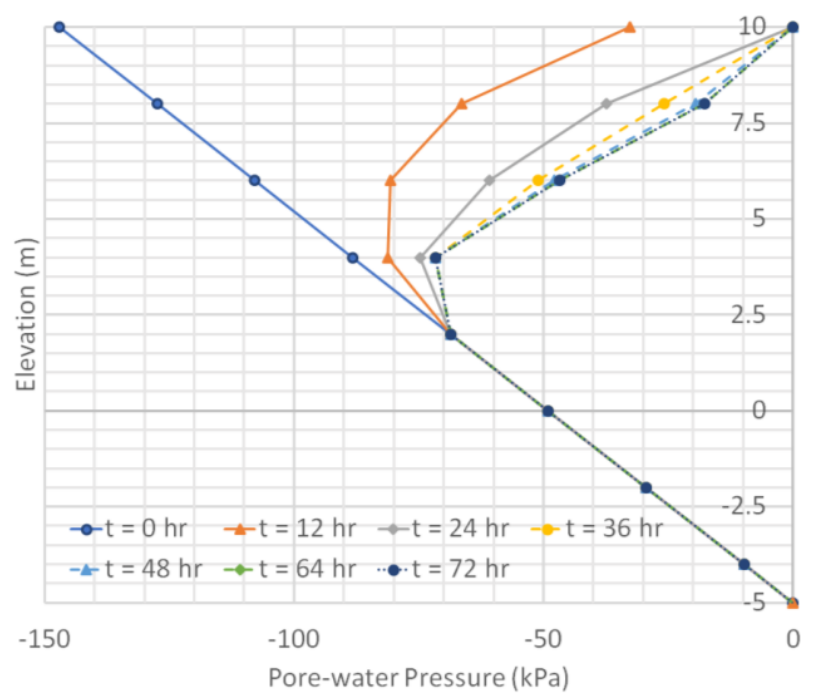

Fig. 11. Change of pore-water pressure at Line 2-8 (Top) for $70^{\circ}$ angle of 10-meter-high slope

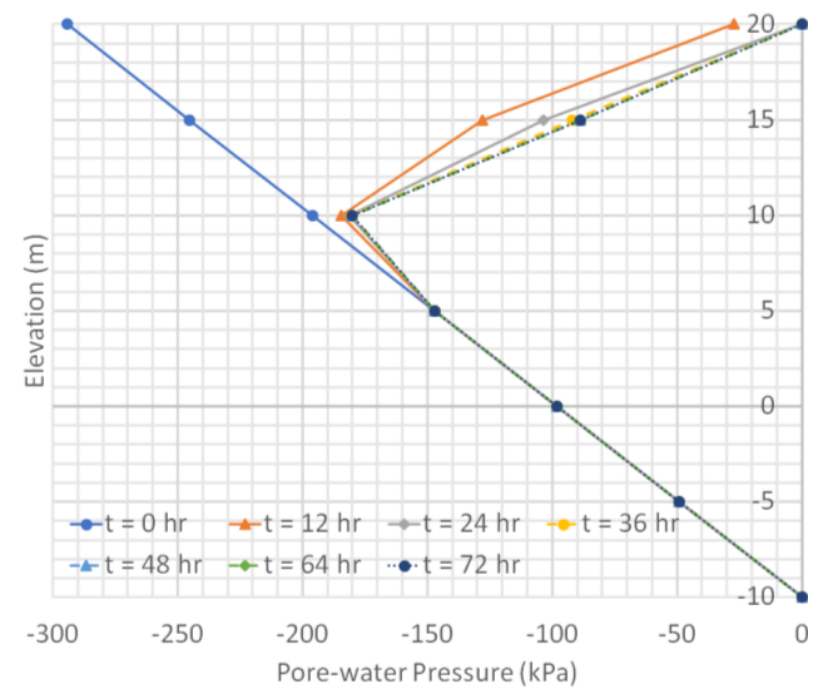

Fig. 12. Change of pore-water pressure at Line 2-8 (Top) for $70^{\circ}$ angle of 20-meter-high slope

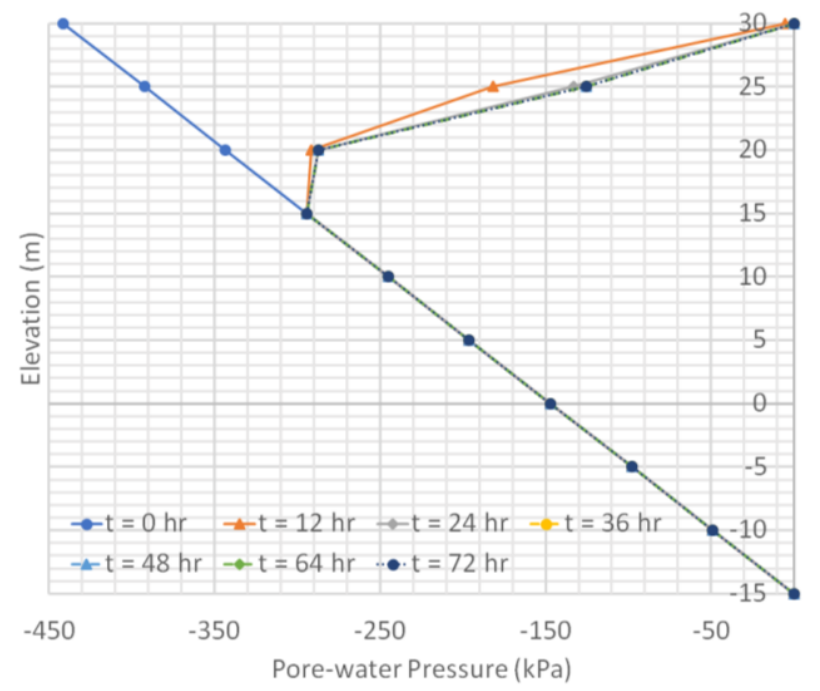

Fig. 13. Change of pore-water pressure at Line 2-8 (Top) for $70^{\circ}$ angle of 30-meter-high slope

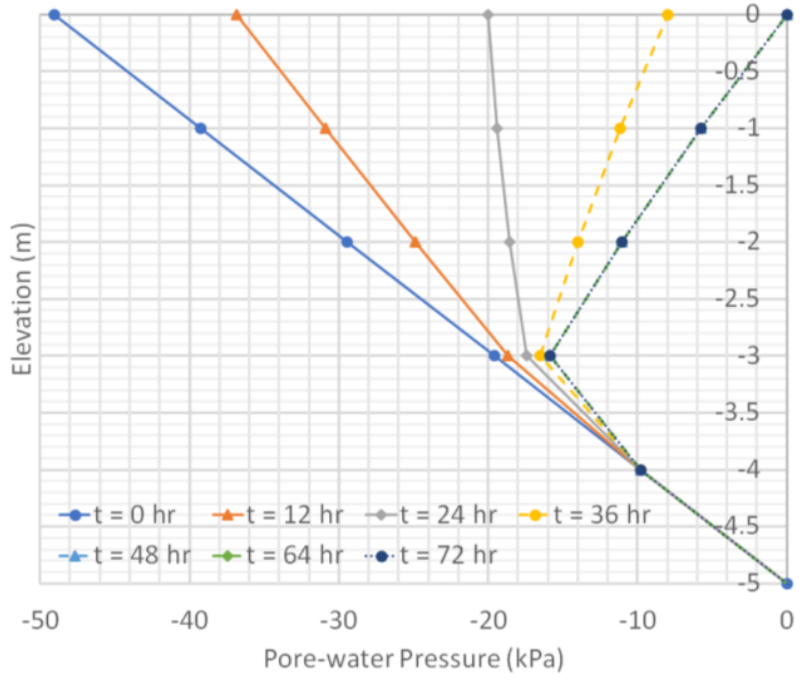

Fig. 14. Change of pore-water pressure at Line 3-9 (Bottom) for $70^{\circ}$ angle of 10 -meter-high slope

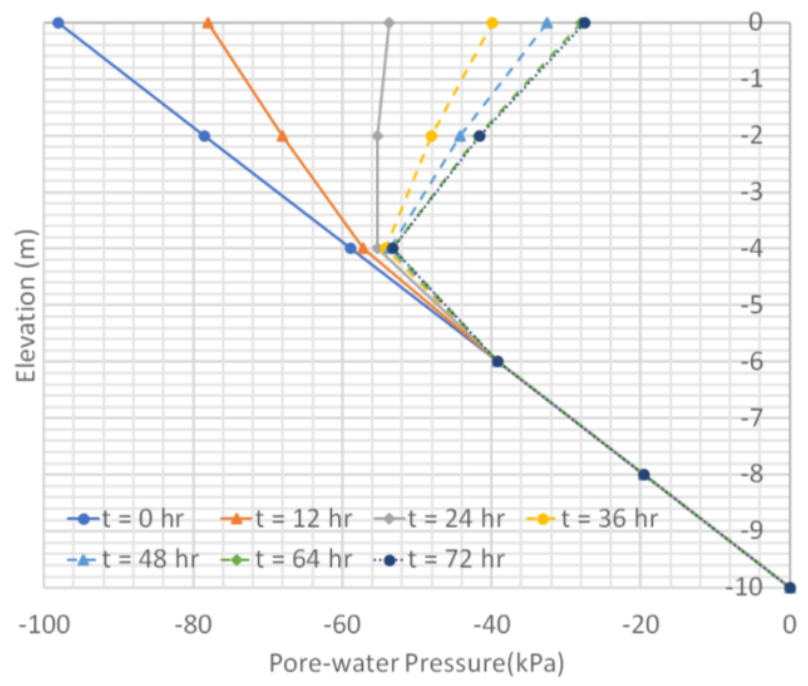

Fig. 15. Change of pore-water pressure at Line 3-9 (Bottom) for $70^{\circ}$ angle of 20 -meter-high slope

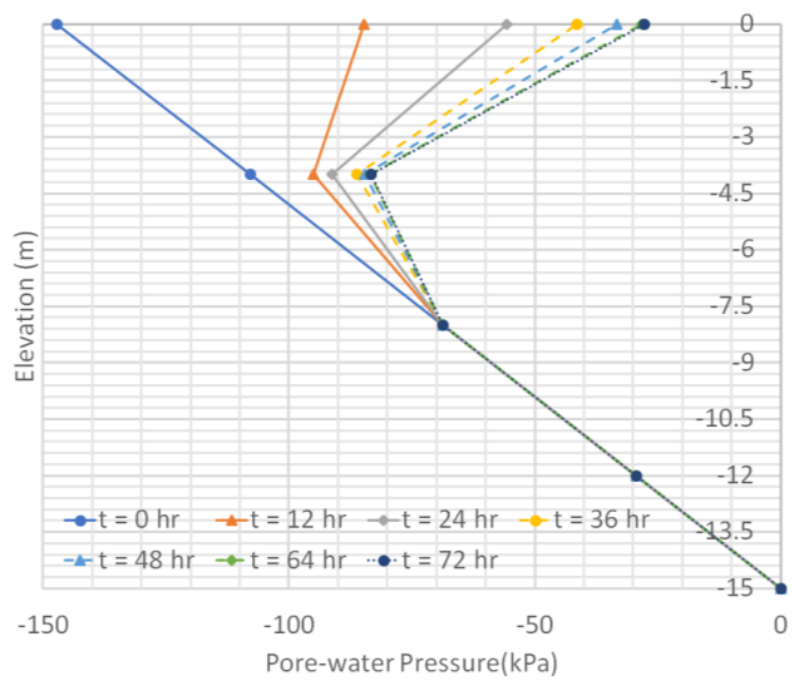

Fig. 16. Change of pore-water pressure at Line 3-9 (Bottom) for $70^{\circ}$ angle of 30 -meter-high slope 
From Fig.11, Fig.12, Fig.13, Fig.14, Fig.15, and Fig. 16 , it is known that the maximum negative pore water pressure for different height is different whereas the greater the height of the slope, the greater the maximum negative pore water pressure. During rainfall, infiltration occurs until the depth of $\pm 5 \mathrm{~m}$ which reduces the negative pore water pressure near the surface. The depth of infiltration of $\pm 5 \mathrm{~m}$ reaches the body of the slope for 10 $\mathrm{m}$, but in ratio will only change the pore water pressure at the surface for the height of $20 \mathrm{~m}$ and $30 \mathrm{~m}$. These findings are consistent with Section 4.2 where the probability of failure increases more significantly for the $10 \mathrm{~m}$ height.

It is also known that at the surface, each of the slope height reaches the $0 \mathrm{kPa}$ pore water pressure as compared to [9] is natural for transient condition where the rainfall intensity is bigger than the hydraulic conductivity of the soil. The value of $0 \mathrm{kPa}$ also indicates that the infiltration at the surface can no longer occur and rainfall will then be complete surface run-off. This change of behaviour explains the stagnant value of probability of failure after the first 24-hour rainfall and gives precautions on handling cut-slopes with such geometries to be careful of landslide cause change from saturated landslide due to rainfall to erosion.

\section{Conclusions}

From the previous sections, there are some conclusions that can be noted.

First, the initial probability of failure until the angle of $55^{\circ}$ for each slope height is quite small but becomes quite big at the angle of $70^{\circ}$ which indicates that the recommended cut-slope angle to be constructed is under $70^{\circ}$.

Second, the most significant change of FS during rainfall is achieved at the height of $10 \mathrm{~m}$ due to the depth of rainfall infiltration that saturates into the body of the slope. The taller the slope, the slower the infiltration reaches the body of the slope which indicates faster failure for shallow slope.

Lastly, due to high rainfall intensity and small hydraulic conductivity, the surface of the slope saturates faster which makes rainfall infiltration occurs quite fast and turned into surface runoff after the high rainfall intensity rain occurs. This notes that for cut-slope of tropical red clay soil, it is important to know that landslides may occur due to erosion after a consecutive high rainfall intensity occurrence.

The authors would like to thank Civil Engineering Department, Universitas Indonesia, especially Soil Mechanic Laboratory staffs and lecturers for the spirit and input of this research.

\section{References}

1. H. Rahardjo, T.H. Ong, R.B. Rezaur, E.C. Leong, J Geotech Geoenviron, 133(12), 1532-1543 (2007)

2. Ministry of Public Works (PU), Perencanaan teknis lereng galian pada material vulkanik dan tanah residual (2015)
3. A.J. Syahbana, A. Tohari, E. Soebowo, D. Sarah, K. Sugianti, JLBG, V 4(1), 33-47 (2013)

4. L.D. Wesley, Geotechnical Engineering in Residual Soils (John Wiley \& Sons Inc., New Jersey, 2010)

5. D.G. Fredlund, The emergence of unsaturated soil mechanics (Fourth Spencer J. Buchanan Lecture, Texas A\&M, 1996)

6. L.D. Wesley, Geotechnique, 27, 125-126 (1997)

7. B.B.K. Huat, F.H. Ali, R.S.K. Rajoo, Am J Environ Sci, 2(4), 154-160 (2006)

8. G.-r. Zhang, Y.-j. Qian, Z.-c. Wang, B. Zhao, Sci. World J., 2014, 7 pg (2014)

9. L. Zhang, J. Li, X. Li, J. Zhang, H. Zhu, Rainfallinduced soil slope failure: stability analysis and probabilistic assessment (CRC Press: Taylor \& Francis Group, Boca Raton, 2016)

10. L.D. Wesley, Geotechnique, 23, 471-494 (1973)

11. M.E. Woodbridge, U.R. Cook, B.S. Saroso, PIARC World Conference Kuala Lumpur (1999) 